\title{
Processes of Cultural Change and Health Education
}

\author{
Alessandra Gargiulo Labriola* \\ Department of Pedagogy, Catholic University of Sacred Heart, Italy \\ *Corresponding author: Alessandra Gargiulo Labriola, Department of Pedagogy, Catholic University of Sacred Heart, Italy \\ To Cite This Article: Alessandra Gargiulo Labriola. Processes of Cultural Change and Health Education. Am J Biomed Sci \& Res. 2019 - 3(6). \\ AJBSR.MS.ID.000735. DOI: 10.34297/AJBSR.2019.03.000735
}

Received: June 13, 2019 | Published: July 11, 2019

\section{Short Communication}

In the era of globalisation, the profound technological transformation of production processes is leading to an important change in both the pace of life and time of work, study and leisure. The strong technological acceleration produced by the fastest means of transport, forces us to travel, to run without considering however the impact of our way of travelling on the environment and on the quality of life in our city. In an ever more interconnected world, which changes with extraordinary rapidity and speed, it becomes urgent to reflect on phenomena that we usually define synthetically with the industry 4.0 [1]. How do we educate ourselves in these profound changes? How to question the opportunities that new generations will have to make a great contribution to human and sustainable development in the future of society. If in the time of St. Jerome the language was latin today is the "digital", the language of the web, big data, internet of things. A new language that changes schools and transforms work into factories permeating every moment of our life in being globally and locally interconnected. The language of the web is a language that lays the foundations of a new humanism and that, therefore, cannot and must never lose sight of the centrality of man. When we confront with the digital world, when we look at an uncertain future, we must never forget the depth and strength of our cultural roots even in the time of "the engineering of flows and the existential processes that we pretend to control with rationality "[2], robotization, digital skills.

Not for homesickness, but rather to rediscover the meaning and significance of common living, in a time of deep complexity. Today in the places of cities, urban and anthropic environments, what are the cultural presuppositions to educate young people to health? Faced with the challenges technologies that improve, increase and rebuild the human, what are the questions on which to dwell to reflect to prepare the man to live in the future incognito? This is, in fact, the pedagogical sense that inspires the educational work in the places that constitute the space and the anthropological scenario of many young generations. To lead young people to live in the fourth industrial, technological and scientific revolution, to lead them to savor the taste of educating to health, presupposes the capacity of services and territorial projects to network around the theme of safeguarding Hygiene as an area of disciplinary confrontation and intended to understand, explain, correct, if necessary, phenomena that involve the environmental balances related to the welfare itself. From this perspective, human well-being can be explained at different levels. Suffice it to read the 17 objectives set out in the UN Agenda 2030 with particular reference to Objective 3 in which it is necessary to "ensure health and well-being for all and for all ages", reinforcing, as provided for in point 3.5 , the prevention and Treatment of substance abuse, including drug abuse and harmful alcohol consumption [3].

From this assumption it is easy to understand the urgency of educating to health without neglecting the big risk factors for the development of alcohol-addiction (the alcoholic binge, the drinking or the drink so much all in one evening) to which are exposed many adolescents [4]. Further levels of deepening human well-being we can find them on the physical, mental, building, urban. These levels make us realize that "the problem of the health of an individual, of a social group, is therefore, in a clear relationship with the general conditions of the space in which it dwells" [5]. It is a living space, a place in which to try to live and solve individual and collective problems, educational problems [6]. A context in which the services to the person (sanitary, educational, cultural) should dialogue and improve individual and collective well-being. However, in a culture marked by the excesses of consumerism it is, in many respects marginal, the idea of assuming an educational perspective that, with regard to health problems, can make a decisive contribution to increasing the strength of a community legitimated by a socioeconomic organization that does not underestimate the adverse effects of its work on the environment. The positive effects produced by the processes of conservation and reproduction of nature in its biological cycles are never studied enough.

It is necessary to know the nature and its operations, in all educational contexts, formal, non formal and informal, so that it is possible to take better behaviours to put in place to contrast the reckless exploitation of the natural resources. An exploitation that will inevitably entail high risks for the survival of the individual and of many populations of the our earth. The importance of a hygiene education becomes central, to prevent diseases and to affirm the value of health as well to be protected all over the world. This is a central issue not only to affirm, according to the national law of the Italian Republic, the negative right not to harm the right to 
health but to affirm the prospect of "protection", which provides attention to the positive duty to put in being the actions and organizing the necessary services to the person to ensure good health. Responsibility and civic sense of the institutions and the environment in which people live are indispensable objectives of a community that affirms the principle of the right to health both of all citizens and of the individual. And it is therefore from a pedagogical and holistic perspective that a specific attention is given to the heuristic importance of health as a common good that is not only a right and a duty of each and every one, but it becomes a prospect of educational culture that offers children, young people, adults and the elderly, the opportunity to rediscover a common sense of belonging to life and, therefore, to the environment from a common sense of respect for the human person.

\section{References}

1. G Alessandrini (2017) Atlante di pedagogia del lavoro, FrancoAngeli, Milano, Italy.

2. P.Malavasi (2019) Educate robots? Vita e Pensiro, Milano, Italy.

3. AA VV (2018) Innovazione e salute, le scoperte più significative della ricerca medica, in Presenza 4(5): 15.

4. N Galli (1988) La famiglia e l'educazione alla salute, Vita e Pensiero, Milano, Italy p. 55.

5. ML De Natale, S Monno (2007) Educare gli adulti, Armando Editore, Roma p. 21.

6. A Pioggia (2017) Diritto sanitario e dei servizi sociali, G Giappichelli Editore, Torino, USA p. 21. 